\title{
A Study of the Optimum Growth Control System Using a Microcomputer ${ }^{\dagger}$
}

\author{
Hiromu NAKAzAWA* and Tsukasa MatsuUra**
}

In this paper we propose a system which will result in the growth of a plant in the shortest time possible through the control of the plant's environment by the realtime system with the aid of a microcomputer.

The proposed system is to control the codition of the house so that apparent photosynthetic rate of the selected plants in the assimilatory box will be maximized.

The feasibility of the system has been confirmed by the experiments such as the compound control of $\mathrm{CO}_{2}$ concentration and air temperature.

In this paper, the control method using a model is also considered for an advanced control.

The model which is used here is a growth model of lettuce and the example of planned production, which satisfies the required items, cost, due time of delivery and weight, is explained and finally the optimum illuminance for the plant factory which is planned by the authors is shown by case study.

Key Words: optimal control, growth model, compound control, plant factory, environmental control

\section{Preface}

Protected cropping in greenhouse has been practised commercially in the North temperature regions of Europe and North America since 1870's. ${ }^{11}$ Most famous recent systems are Cristensen Farm in Denmark, Ruthner system in Austria and General Electric, General Mills and General Foods

†第 22 回計測制御学会学術講演会で発表（昭 58.7)

* School of Science and Engineering, Waseda University, Shinjuku-ku, Tokyo

** Laboratory for Materials, Mitsubishi Electric Corp. Amagasaki (Received March 12, 1984)

(Revised July 28, 1984) systems in U.S. A.. In Japan Hitachi has made a lot of contributions in this field. ${ }^{2)}$ Hashimoto has also proposed the concept of computer-aided cultivation. $^{3)}$

Most of them, however, are based on the program control according to the preset conditions. But the optimum condition for plant is not constant and varies time to time depending on its past life, growth period, mutual relation of the environmental factors, and so on.

In this paper, we propose the optimum environmental control system, constantly getting the biological information and making the realtime control, and confirm the efficiency of this system by some experiments, and also for an advanced control system, propose a control method using a growth model.

\section{Method of environmental control}

The purpose of this system is to force vegetables by giving optimum conditions controlled by a microcomputer. The outline of the system is shown in Fig. 1. In this system, green vegetables are cultivated and the apparent potosynthetic rate (decreasing rate of $\mathrm{CO}_{2}$ ) is chosen as the growth index.

Plants are grown in the sealed house and the environmental conditions such as temperature, humidity, $\mathrm{CO}_{2}$ concentration and illumination are controlled evenly for every plant. A few plants,

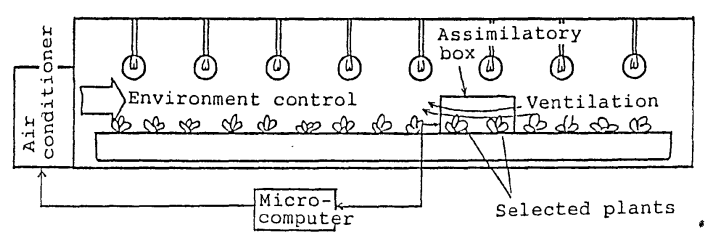

Fig. 1 The outline of the optimal control system 
which are arbitrarily chosen, are covered with the assimilatory box, which is covered with a tansparent vynil sheet. The inside condition of the assimilatory box is held to be equal to the outside condition by ventilation. The condition of the house is controlled so that the photosynthetic rate of the selected plants in the assimilatory box will be maximized. Thus in this system a few selected plants represent the whole ones.

\section{Preliminary experiments}

Preliminary experiments were made in order to know the fundamental relations between environmental factors and photosynthetic rate.

The control system for the experiment is shown in Fig. 2. An assimilatory box covered with a transparent vinyl sheet and equipped with two doors for ventilation is settled in the growth chamber and a few heads of lettuce are cultivated by hydroponics. The condition inside the growth chamber is controlled by the microcomputer.

When the photosynthetic rate is measured, the two doors are closed and the fan rotates slowly to homogenize the air condition, and when not measured, the doors are wide open and the fan runs to ventilate.

\subsection{Relation between air temperature and photosynthetic rate}

From $10[\mathrm{deg}]$ to $35[\mathrm{deg}]$, photosyntetic rate was measured 10 times at each temperature. The result is shown in Fig. 3. The relation shows the

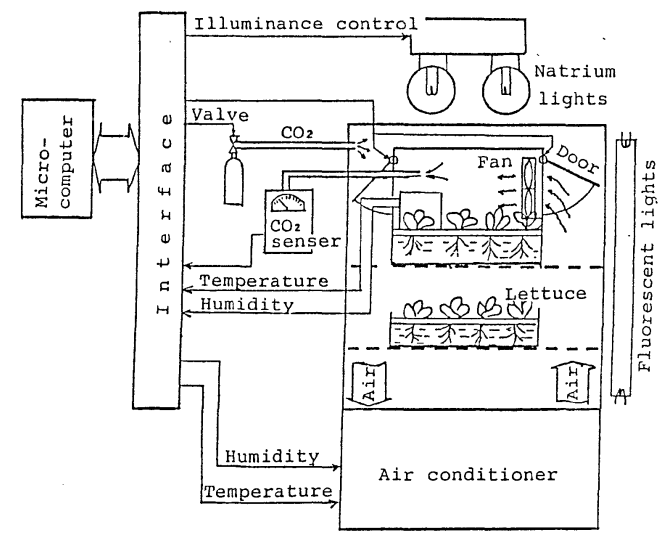

Fig. 2 The optimal control system for the experiment optimum curve with the maximum point at about 15 [deg].

\section{2 Relation between $\mathrm{CO}_{2}$ concentration and photosynthetic rate}

$\mathrm{CO}_{2}$ concentration was varied from $600[\mathrm{ppm}]$ to 4600 [ppm] by $400[\mathrm{ppm}]$ and the photosynthetic rate was measured 5 times at each comcentration. As shown in Fig. 4, photosynthetic rate is saturated at about $3000[\mathrm{ppm}]$ for both temperature, 20 [deg] and 34 [deg].

\section{3 Relation between illuminance and photo- synthetic rate}

Illuminance was changed from $0[1 \mathrm{x}]$ to $50[\mathrm{k} 1 \mathrm{x}]$ and photosynthetic rate was measured 5 times at each setting. It is commonly said that the light saturation point of lettuce is about $25[\mathrm{k} 1 \mathrm{x}]$, but in this experiment as shown in Fig. 5 the curve has an increasing tendency even at $50[\mathrm{k} 1 \mathrm{x}]$. This

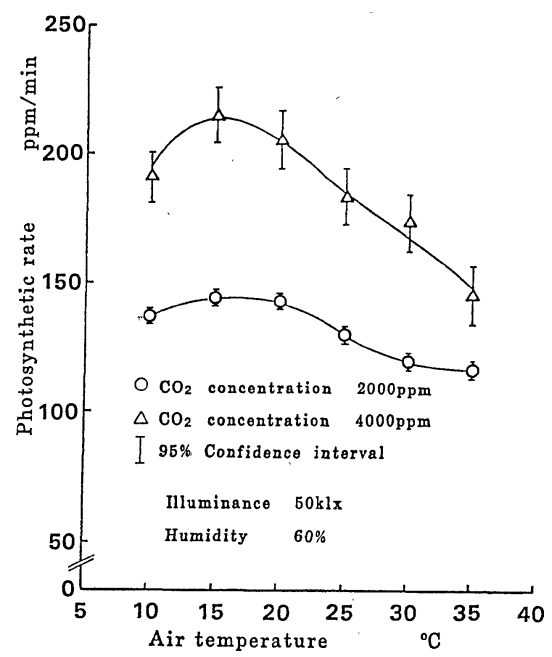

Fig. 3 Relation between air temperature and photosynthetic rate

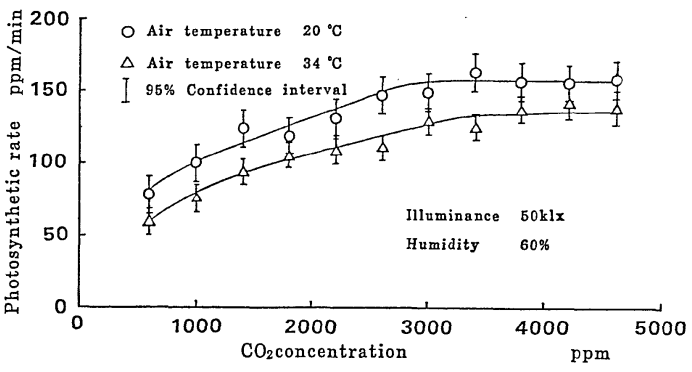

Fig. 4 Relation between $\mathrm{CO}_{2}$ concentration and photosynthetic rate 
phenomenon may be caused by the leaves which are indirectly or insufficiently illuminated and do not yet reach the light saturation point.

\section{Optimal control experiments}

\subsection{Optimal control of air temperature}

As the preliminary experiment shows, there exists an apparent maximum point or the optimum point of the photosynthetic rate to temperature.

The result is shown in Fig. 6. It is determined by the following steps. The search began at 14 [deg], increasing temperature step by step by 6 [deg], measuring the photosynthetic rate at each temperature, and when the photosynthetic rate became lower than former one, decreased the temperature by half interval. The search was repeated until the interval became shorter than 1 [deg]. In this experiment the optimal temperature was 20 [deg].

\subsection{Optimal control of $\mathrm{CO}_{2}$ concentration}

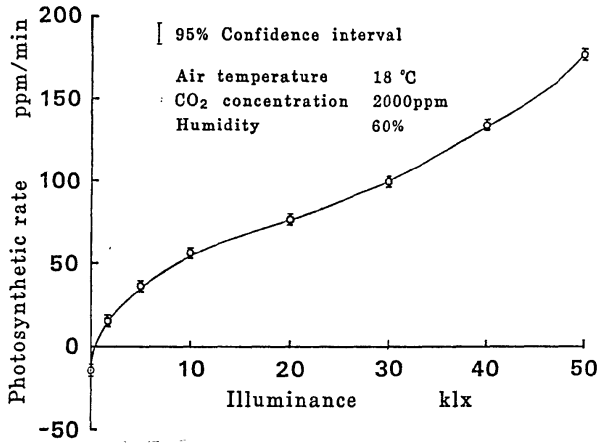

Fig. 5 Relation between illuminance and photosynthetic rate

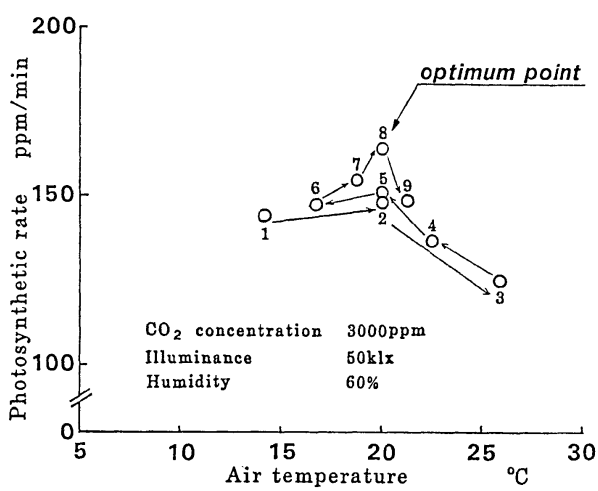

Fig. 6 Optimal control of air temperature
As for $\mathrm{CO}_{2}$ concentration, the saturation point is regarded as the optimum point. It was obtained by the search starting with the lower concentration, making it higher step by step, examining the statistical significance of photosynthetic rate at adjacent measuring points.' When the difference of the photosynthetic rates between two concentrations is not statistically significant, this point is not statistically significant, this point is taken as the saturation point or the optimum point (Fig. 7).

\subsection{Compound control of Temperature and $\mathrm{CO}_{2}$ concentration}

In this experiment the Hooke and Jeeves' algorithm ${ }^{4)}$ which was modified in order to examine the statistical significance when the search proceeds parallel to the axis of $\mathrm{CO}_{2}$ concentration was used.

The result is shown in Fig. 8. The optimum

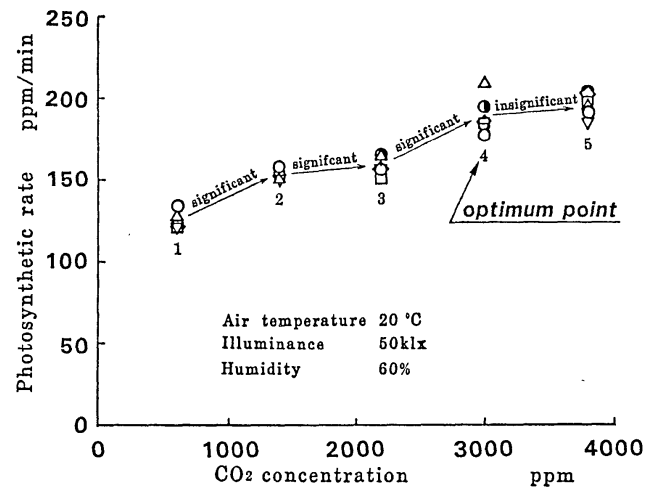

Fig. 7 Optimal control of $\mathrm{CO}_{3}$ concentration

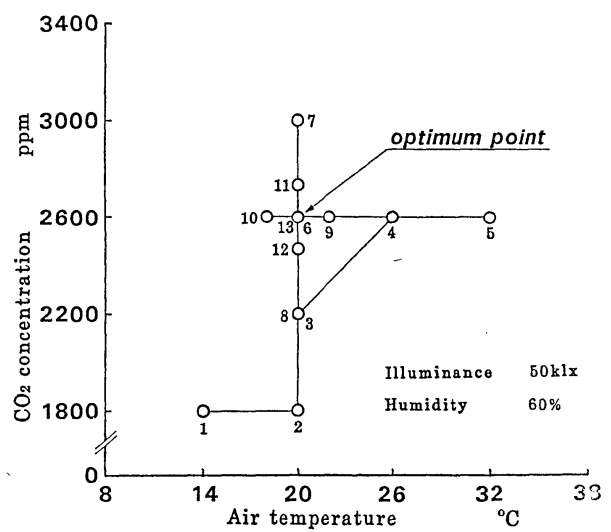

Fig. 8 Compound control of air temperature and $\mathrm{CO}_{2}$ concentration 
point is at No. 13 with 20 [deg] of temperature and $2600[\mathrm{ppm}]$ of $\mathrm{CO}_{2}$ concentration.

\section{Optimal control with growth model}

The most important purpose of the plant factory is the planned production, in other words, to regard the plants as the manufactured goods and produce them evaluating the requied items such as time limit of delivery, cost and quality. In order to realize it, anticipation from the model is indispensable.

In this chapter an example of the planned production using a growth model will be shown.

\section{1 Case study}

Assume that lettuce is produced and that three required items, biological information and the environmental factor for control are given as follows.

$<$ Required items $>$

1) Weight of one head $\cdots 100[\mathrm{~g}]$

2) Due date of delivery $\cdots$ Within 35 days

3) Cost $\cdots$ Minimum

$<$ Biological information $>$

Weight

$<$ Environmental factor for control $>$

Illuminance

From Fig. 5 it is shown that the higher the illuminances becomes, the higher the photosynthetic rate is obtained and the faster the plant grows. Thus growth models depending on illuminance are obtained as shown in Fig. 9(a), and the dates needed for the plant to reach 100 [g] depending upon illuminance is obtained as shown in Fig. $9(\mathbf{b})$.

The planned production, satisfying two required

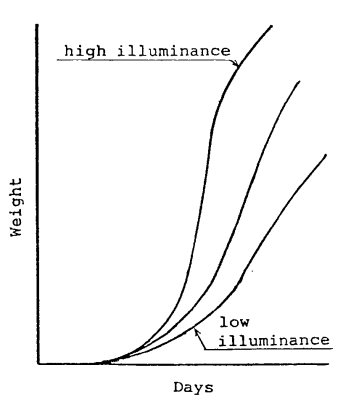

(a) Growth models depending on illuminance

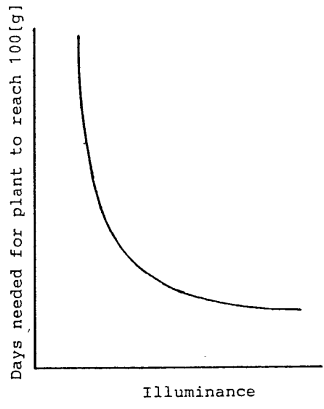

(b) Dependence of the growth days on illuminance items, weight and due date, can be done by giving the plant's weight and controlling illuminance with reference to these figures. Moreover with the consideration of power cost, which is a linear function of illuminance as shown in Fig. 9(c), the production satisfying the three required items will be done.

\subsection{Adaption of actual data}

The actual data from the experiments are adapted to the case study in order to forecast the optimum condition such as illuminance whose optimum point could not be decided in 3.3.

(1) Growth model

Growth model is formularized as Eque. $(1)^{2)}$.

$$
d M / d t=A M^{\alpha}+B M
$$

$M:$ Weight $[\mathrm{g}]$

$A:$ Real photosynthetic rate $[\mathrm{ppm} / \mathrm{min}]$ $(A>0)$

$B$ : Respiration speed $[\mathrm{ppm} / \mathrm{min}](B<0)$

$\alpha$ : Constant $(2 / 3<\alpha<1)$

Solution of the above equation is obtained as follows.

$$
M=M_{\infty}\left[1-e^{(1-\alpha)} B t\right]^{1 /(1-\alpha)}[\mathrm{g}]
$$

$M_{\infty}$ : Final Weight $[\mathrm{g}] \quad\left(=|A / B|^{1 /(1-\alpha)}\right)$

The actual data at $20\left[{ }^{\circ} \mathrm{C}\right], 3000[\mathrm{ppm}] \mathrm{CO}_{2}, 50$ [klx] and $60[\%]$ humidity are simulated by the equation as follows.

$$
M=400\left(1-e^{0.059 t}\right)^{10.2}[\mathrm{~g}]
$$

This curve is shown in Fig. 10.

(2) Illuminance and photosynthetic rate

Relation between illuminance and photosynthetic rate is formularized by the equation,

$$
P=\frac{b I}{1+a I}-R+c I[\mathrm{ppm} / \mathrm{min}]
$$

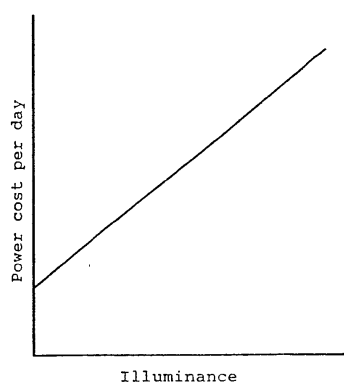

Fig. 9

Typical models for the example 


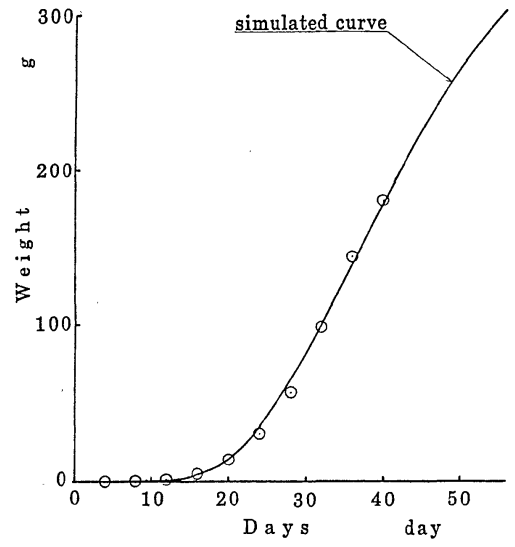

Fig. 10 The growth curve of lettuce

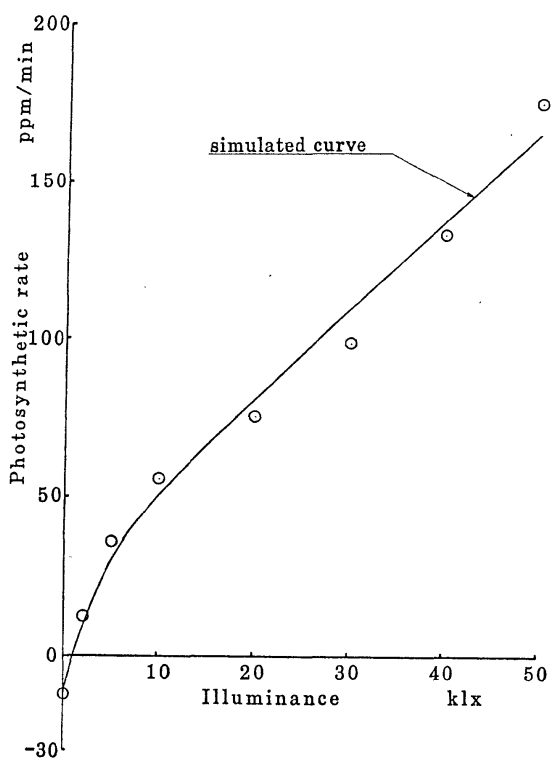

Fig. 11 Relation between illuminance and photosynthetic rate

$P$ : Real photosynthetic rate $[\mathrm{ppm} / \mathrm{min}]$

$I$ : Illuminance $[\mathrm{klx}]$

$R:$ Respiration speed $[\mathrm{ppm} / \mathrm{min}] \quad(<0)$

$a, b, c:$ Constants

The real data was simulated by this equation as follows at the same conditions as above,

$$
P=\frac{0.02 I}{1+4.4 \times 10^{-4} I}+13.74+27.5
$$

[ppm/min] (5)

Thus the apparent photosynthetic rate $\mathrm{Pa}$ is,

$$
P a=P-13.74[\mathrm{ppm} / \mathrm{min}]
$$

This equation is shown in Fig. 11 with the actual data.

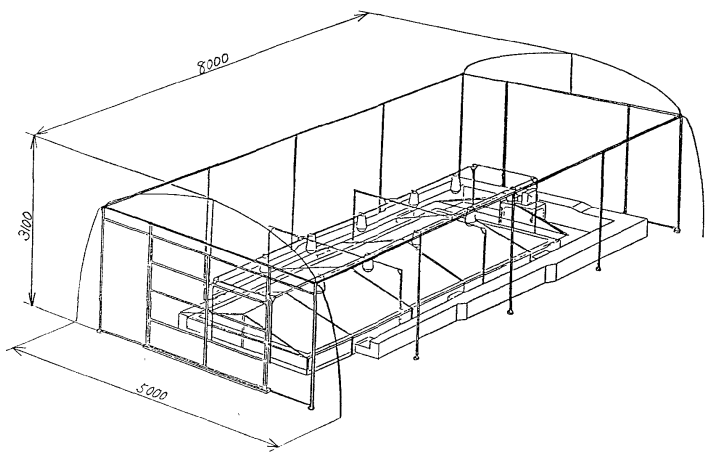

Fig. 12 Plant factory planned

plant lettuce

cropping amount 11000 pieces/year

weight of plant $\quad 100 \mathrm{~g}$

capacity of air $\quad 9000 \mathrm{kcal} / \mathrm{h}$

conditioner

power of air $\quad 4 \mathrm{~kW}$

conditioner

lamp

control parameter

computer

$270 \mathrm{~W} \times 10$

temperature, $\mathrm{CO}_{2}$ concentration, illumination personal computer

RAM 48 kbite

ROM 6 kbite

(3) Growth model depending on illuminance Because the variable " $A$ " in the Equ. (1) and " $P$ " in Equ. (5) are both real photosynthetic rates, the growth model with parameter of illuminance is obtained by eliminating these variables from the equations.

(4) Cost and optimum illuminance

Power cost, which varies with facilities and the season, was estimated from the specification of the plant factory we planned, which is shown in Fig. 12.

Power cost consists of that of illumination and air cooling.

(a) Power cost of illumination

Power cost of illumination per day $C i$ is shown as follows.

$$
C i=22.0 \times 24 \times W=528 W \text { [Yen] }
$$

$W$ : Power of illumination [kW]

In this equation it is supposed that the electric fee is 22.0 [yen $/ \mathrm{kW} . \mathrm{h}$ ] and the plant is illuminated for 24 hours a day.

(b) Power cost of air cooling

The cooling ability is $9000[\mathrm{kcal} / \mathrm{h}]$ and the necessary power of the air conditioner is $3.92[\mathrm{~kW}]$. 


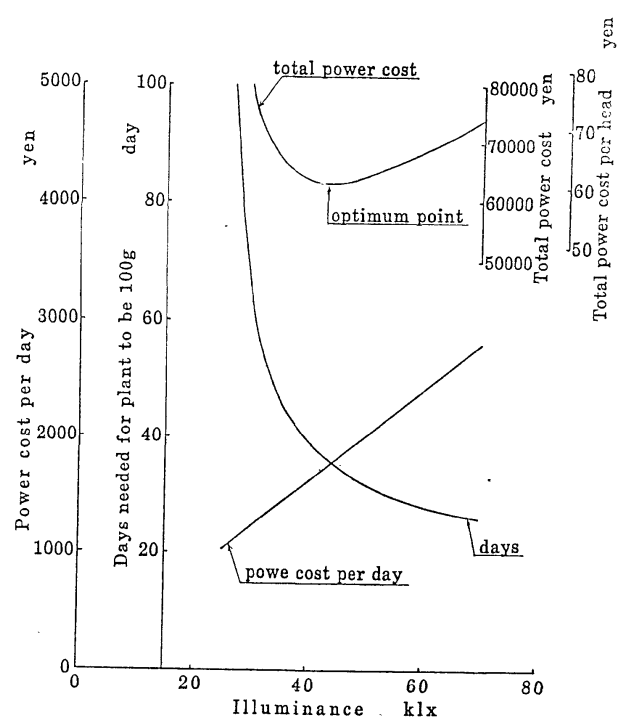

Fig. 13 Power cost and optimum illuminance

The power cost for air conditioning per day $C c$ is obtained by the equation,

$$
C_{c}=\frac{Q}{9000} \times 3.92 \times 22.0=9.58 \times 10^{-3} Q[\text { yen }]
$$

$Q$ : Cooling load [kcal]

$Q$ is expressed as follows.

$$
Q=G \cdot k c \cdot \int_{\mathrm{day}}(T o-T e) d t+24 \times 860 W[\mathrm{kcal}]
$$

where the first term is the load caused by heat conduction and the second term is the load by heat of illumination.

$G$ : Area of the convering $\left(=22.3\left[\mathrm{~m}^{2}\right]\right)$

$k c:$ : Heat conductivity of the convering $(=55.0)$

To: Outside temperature

$T e$ : Setting temperature $(=20.0[\mathrm{deg}])$

Thus $C c$ becomes as follors.

$$
C c=198 W+1.17 \int_{\mathrm{day}}(\text { To-20.0)dt [Yen }]
$$

Thus the power cost per day $C e$ is obtained by Equ. (11).

$$
\begin{aligned}
C e & =C i+C c \\
& =726 W+1.17 \int_{\text {day }}(T o-20.0) d t[\text { yen }]
\end{aligned}
$$

On the other hand from the experiment illumi- nance is expressed by the power of illumination as follows.

$$
I=\frac{50.0}{2.70} W=18.5 \mathrm{~W}[\mathrm{klx}]
$$

Thus the power cost per day is shown as follows.

$$
C e=39.2 I+1.17 \int_{\text {day }}(T o-20.0) d t \text { [Yen] }
$$

As the value of $\int_{\text {day }}(T o-20.0) d t$ varies with the seasons, it is decided to be 56.4 , which is the mean value of 6 months, from May to October.

Then the power cost per day is formularized as follows.

$$
C e=39.2 I+66.0 \text { [Yen }]
$$

This curve is shown in Fig. 13.

Finally the total power cost is obtained by (power cost per day) $\times$ (dates needed for plant to be 100 [g]) and is showen in Fig. 13. The required items are weight (100[g]), due date (within 35 days) and cost (minimum), thus the minimum point of the curve can be regarded as the optimum point. The optimum illuminance is $43[\mathrm{klx}]$ and the growth date is 35 [days] and power cost is 60.5 [yen].

\section{Conclusion}

1) The feasibility of the proposed system has been confirmed by the experiments.

2) The basic planned production, which satisfies the required items such as cost, due date of delivery and weight, has been realized and the optimum illuminance for the plant factory has been shown by the case study.

The authors gratefully acknowledge the help given by Shin'Ichi Inoue, Minoru Watanabe, Shuji Kojima and Akihiro Daikoku.

\section{References}

1) D. Rudd Jones: Environmental Control in Vegetable Crop Management. Phytotronic Newsletter, 19, Feb. (1979)

2) Masamoto Takatsuji: Elementary Knowledge and Practice of Plant Factory (in Japanase), Gijutsu Jyoho Center) (1982)

3) Y. Hashimoto, et al.: Computer Processing of Speaking Plant for Clime Control and Computer Aded Plantation. Acta Hor. ticulturae, 115, (1980)

4) L. C. W. Dixon: Nonlinear Optimization, Trans. by Shoichi Matsubara, Baihusha (1972) 